\title{
Numerical investigations of stainless steel melt motions on the surface of uranium dioxide
}

\author{
Eduard V. Usov", Pavel D. Lobanov, Ilya A. Klimonov, Alexander E. Kutlimetov, Anton A. \\ Butov, Vladimir I. Chukhno, Ivan G. Kudashov, Alexander I. Svetonosov, \\ and Nikolay A. Pribaturin
}

Nuclear Safety Institute of the Russian Academy of Sciences, Novosibirsk Branch, Novosibirsk, 630090, Ak. Lavrentiev Ave., 1, Russia

\begin{abstract}
The paper contains the results of numerical simulation of stainless steel melt motions on the surface of uranium dioxide. The investigations are performed for purposes of understanding of the fuel rod behavior during the core disruptive accident in the fast reactors. The systems of mass, energy and momentum conservation equations are solved to simulate melt motion on the surface of the fuel pin. Heat transfer and friction between melt and pin's surface and melt and coolant flow are taken into consideration. The dependences of mass of the melt and the features of the melt motion on coolant velocity and contact angle between melt and surface of the fuel rod are presented.
\end{abstract}

\section{Introduction}

Core disruptive accidents are characterized by fuel rods assembly destruction with release of huge amount of fission products. The fuel rod destruction may be caused by several reasons. The first reason is a mechanical destruction due to large mechanical stress of stainless steel fuel cladding. The second reason is a melting of fuel rod due to overheating. The first mechanism is realized in fuel rods with large burnout. These types of rods are characterized by low yield stress of fuel cladding with compare of fuel rods with low burnout. Thermal destruction is the mechanism of destruction of the rods with low burnout.

The second mechanism is the main object of the presented investigation. The importance of this mechanism connected with the fact that melting of fuel rods is the most dangerous for reactors safety and can cause irreversible sequences in the reactor operation. In the paper the features of stainless steel melt motion on the surface of uranium dioxide are discussed.

\section{Basic models}

To perform the numerical simulation of fuel pins thermal destruction it is necessary to simulate melt formation and relocation of the melt. The most difficult is the simulation of

*Corresponding author: usovev@gmail.com 
melting and relocation at the same moment. To overcome the difficulties the heat transfer problem should be solved at first. After solving the heat transfer problem the temperature field and the mass of melt are determined. Then the system of mass, energy and momentum conservation equations is solved to simulate melt motion. The heat transfer between melt and fuel rod's surface is simulated at the first stage. Both two stages take place at the same step $[1,2]$. The example of the momentum equation is presented below:

$d \rho_{m} S U_{m} / d t+d \rho S U_{m}^{2} / d z=-S d p / d z+\Gamma U_{m}+\rho_{m} g S \cdot \sin \theta+\tau_{c} \Pi_{c}-\tau_{w} \Pi_{w}+\sigma \Pi_{w} \cos \theta_{w} \cdot \delta\left(z-z_{i}\right)$

$S$ - cross section of the melt, $\mathrm{m}^{2} ; \Gamma$ - mass source; $p$ - pressure, $\mathrm{Pa} ; U_{m}$ - velocity of the melt, $\mathrm{m} / \mathrm{s} ; \tau_{c}, \tau_{w}-$ interfacial and wall shear stress, $\mathrm{H} / \mathrm{m}^{2} ; \sigma-$ surface tension, $\mathrm{N} / \mathrm{m} ; \theta_{w} \cdot-$ contact angle.

The value of melt movement velocity depends on flow regime. There are two basic regimes. The first one is a film flow regime. The film flow regime is typical for stainless steel melt motion during loss-of-coolant accident. The second one is a continuous flow regime. This regime is typical for uranium dioxide melt motion during transient-over-power accident. Laminar and turbulent flow are sub modes for each regime. Gravitational forces, viscous forces, surface tension and pressure gradient determine the direction and the value of the melt velocity. Viscous forces depend on friction coefficient between melt and surface of fuel rod. Friction and heat transfer coefficients, cross-sectional area of melt and wetted perimeter depend on flow regime.

\section{The results of simulation}

In order to simulate melt motion on the surface of uranium dioxide the fuel rod model was constructed. The model was $2 \mathrm{~m}$ long. There are three part of the fuel rod. The first part was $1 \mathrm{~m}$ long. The second and third parts were $0,5 \mathrm{~m}$ long (figure 1). Uranium dioxide was placed in the central part of fuel rod. The diameter of fuel pellet was equal $0,004 \mathrm{~m}$. The fuel rod had a stainless steel cladding. The inner and outer diameter of the cladding were equal $0,004 \mathrm{~m}$ and $0,0045 \mathrm{~m}$ respectively. The heat released only in the first part of the fuel rod. The value of heat release was equal $0,5 \cdot 10^{6} \mathrm{~W} / \mathrm{m}^{2}$. The initial value of the fuel rod temperature was equal $600 \mathrm{~K}$. The presented parameters were closed to the parameters of the real fuel rod [Ошибка! Источник ссылки не найден.].

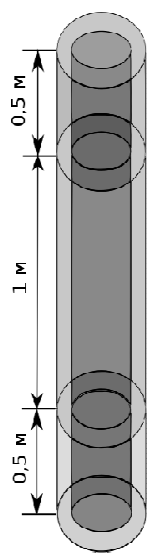

Fig. 1. The fuel rod model.

Boiling of coolant can occur during the accident. Intensive boiling can cause dryout of coolant film and melting of fuel rod. The velocity of coolant vapor can achieve $100-150$ 
$\mathrm{m} / \mathrm{s}$ [4]. The high velocity value of coolant vapor has a strong influence on melt relocation. So it is necessary to simulate friction between melt and gas flow. To investigate the features of melt relocation different values of gas velocity were considered: $10 \mathrm{~m} / \mathrm{s}, 50 \mathrm{~m} / \mathrm{s}, 100$ $\mathrm{m} / \mathrm{s}, 150 \mathrm{~m} / \mathrm{s}$

Friction stress $\tau$ between gas flow and melt can be evaluated by the following way:

$$
\tau=\xi \cdot \rho_{g} \cdot\left(U_{g}-U_{m}\right)^{2} / 8
$$

where $\rho_{g}$ is a density of gas, $U_{g}$ is a velocity of gas, $U_{m}$ is a melt velocity, $\xi$ is a friction coefficient. To calculate the friction coefficient, we can use the following equation [5]:

$$
\xi=0,02 \cdot(1+300 \cdot \delta / D)
$$

$\delta$ is a film thickness, $D$ is a channel diameter.

The influence of contact angle between stainless steel melt and uranium dioxide were considered too: $70 \mathrm{deg}, 90 \mathrm{deg}, 110 \mathrm{deg}, 130 \mathrm{deg}$. The main goals were the determination of mass quantity that left the central part of the fuel rod.

At first, the dependence of calculation results from the calculation grid was investigated. The results for different number of calculation cells are presented in figure 2 . As we could see from the figure 2, 160 cells are sufficient for convergence of the results of calculation.

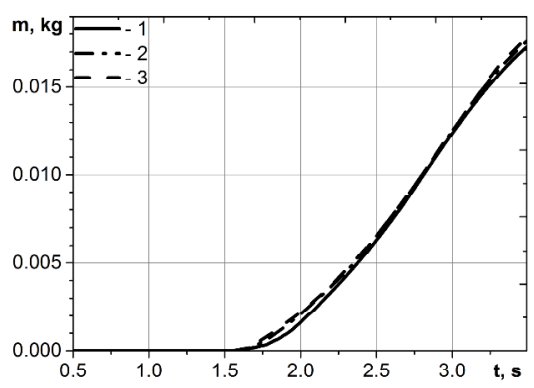

Fig. 2. Mass of the melt. The results of simulation for a different number of calculation cells. $1-40$ cells; $2-80$ cells; 3 - 160 cells.

Distribution of materials for different time moments is presented in the figure 3 . The mass quantity that left the central part of the fuel rod for different gas flow velocity is presented in figure 4.
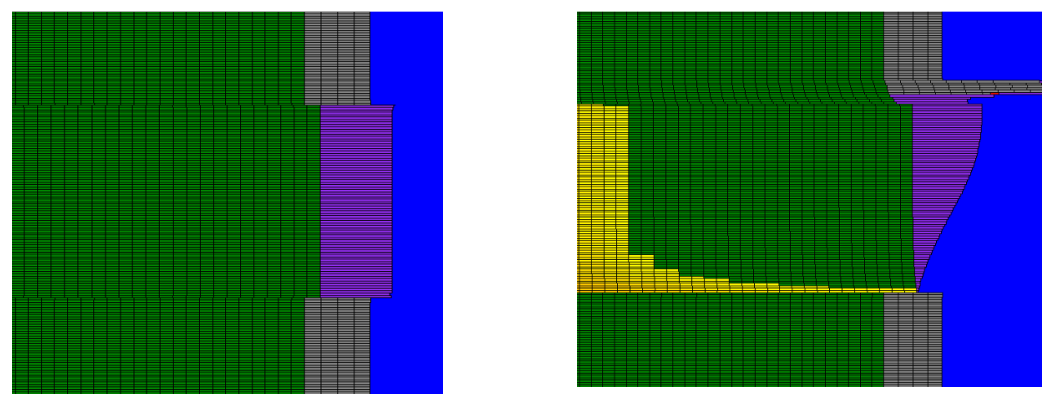

Fig. 3. The distribution of materials for different time moments. Left $-1,56 \mathrm{~s}$. Right $-2,9 \mathrm{~s}$. Green uranium dioxide in solid state. Yellow - melt of uranium dioxide. Purple - melt of stainless steel. Grey - stainless steel in solid state. 


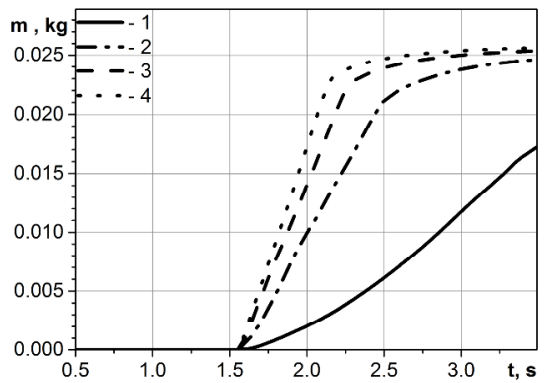

Fig. 4. The mass of the melt. The results of simulation for a different value of the gas flow velocity. 1 $-10 \mathrm{~m} / \mathrm{s}, 2-50 \mathrm{~m} / \mathrm{s}, 3-100 \mathrm{~m} / \mathrm{s}, 4-150 \mathrm{~m} / \mathrm{s}$.

The mass quantity that left the central part of the fuel rod for different contact angle and for gas velocity that equal $100 \mathrm{~m} / \mathrm{s}$ is presented in figure 5 . As we can see the contact angle influence is negligible.

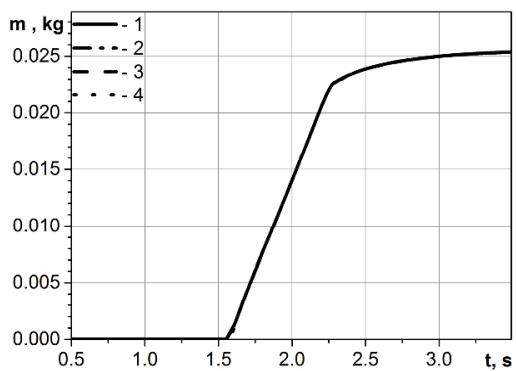

Fig. 5. The mass of the melt. The results of simulation for a different value of the contact angle. 1 $70 \mathrm{deg} ; 2$ - $90 \mathrm{deg} ; 3$ - $110 \mathrm{deg} ; 4-130 \mathrm{deg}$.

\section{Conclusions}

On the base of realized numerical model the simulations of the stainless steel melt relocation were provided. The simulations were made for different value of the coolant velocity. It was shown that coolant velocity strongly influence on the melt motion.

The work was performed at support of the projects funded by the Russian Science Foundation (RSF № 18-79-10013).

\section{References}

1. E.V. Usov, A.A. Butov, V.I. Chukhno et all, Atomic Energy, 124, 4 (2018) (in Russian).

2. E.V. Usov, A.A. Butov, V.I. Chukhno et all, Atomic Energy, 124, 5 (2018) (in Russian).

3. K. Konishi, J. Toyooka, K. Kamiyama, et. all. Nucl. Eng. Des., 237 (2007).

4. G.B. Usynan, Yu.I. Anoshkin, M.A. Semenychev, Sov. Atomic Energy, 70, 2 (1991).

5. G. Wallis, One-dimensional two-phase flow (McGraw-Huill, New York, 1969). 